\title{
Thermal decomposition and fire extinguishing mechanism of CF3I: a combined theoretical and experimental study
}

\author{
Rourou $\mathrm{Yu}^{1}$, Wenhao $\mathrm{Hu}^{1}$, Xiao Zhang ${ }^{2}$, Xingyu Wang ${ }^{2}$, and Zhaoyang $\operatorname{Tan}^{1}$ \\ ${ }^{1}$ Hebei University of Technology \\ ${ }^{2}$ Civil Aviation University of China
}

August 4, 2021

\begin{abstract}
The urgent desire for Halon substitution propels the exploration of potential alternatives, because of the severe damage of Halons to the stratospheric ozone layer. In this paper, the thermal decomposition mechanism, as well as fire-extinguishing mechanism and performance of Trifluoroiodomethane (CF3I) were studied by density functional theory (DFT) calculation and experimental measurements, to analyze the practicability of this proposed Halon substitute. The thermal decomposition products of CF3I can react with active $\mathrm{OH}$. and $\mathrm{H}$ - radicals to achieve the purpose of rapidly fire-extinguishing. Besides, through DFT calculation and reaction kinetics analysis, the fire-extinguishing radicals CF3. and I- are more easily generated during the interaction between CF3I and flame, which indicates the chemical- extinguishing mechanism and pronounced fire-extinguishing performance of CF3I. To explore its actual fire-extinguishing effect, the fire-extinguishing concentration (FEC) of CF3I was measured in cup burner. The FEC value of this proposed Halon substitute is $3.42 \mathrm{vol} \%$ for extinguishment of methane-air flame, which is smaller than those of three HFCs and HFO-1336mzz(Z) and is comparable to that of Halon 1301. These findings suggest the promising applicability of CF3I in practical Halon replacement and the necessity of further evaluation.
\end{abstract}

\section{Introduction}

"Halon" $1301\left(\mathrm{CF}_{3} \mathrm{Br}\right)$ and "Halon" $1211\left(\mathrm{CF}_{2} \mathrm{ClBr}\right)$ are widely used high-performance fire-extinguishers. However, Halons are ozone-depleting substances (ODSs) and synthetic greenhouse gases (GHGs), which caused serious damage to the ozone layer and had a significant impact on the ecological environment. Therefore, the Montreal Protocol (1987) and subsequent amendments have prohibited the production and usage of Halons and Chlorofluorocarbons (CFCs). Besides, the European Union is requested to accomplish the replacement of Halon 1301 and 1211 in newly constructed aircraft by 2018 and in existing ones by 2040. Therefore, the exploration for low ozone depletion potential (ODP) and pronounced fire-extinguishing performance is of crucial significance ${ }^{1-3}$.

Among the product candidates for Halon substitutes, Hydrofluorocarbons (HFCs), 2-bromo-3, 3, 3trifluoropropane (2-BTP) and perfluoro2-methyl-3-pentone (PFMP) products have been well studied and were considered as potential alternative to clean fire-extinguishing agents. For example, HFC-227ea is a colorless, odorless, low-toxic and non-conductive clean gas. It has good thermal and chemical stability ${ }^{4}$ and can reliably extinguish fires with a low concentration (6.3vol\%). $\mathrm{PFMP}^{5}$ was found to be a Halon substitute owing to its negligible global warming potential (GWP), zero ODP, and promising fire-extinguishing performance. And 2-BTP was considered as the potential replacement ${ }^{6}$, because it has an atmospheric lifetime of days to weeks and can be removed from the atmosphere by $\mathrm{OH}$. radicals in the photolysis reaction ${ }^{7}$. Despite the obvious advantages of the above alternatives, HFCs, 2-BTP, and PFMP also have drawbacks to a certain 
extent that limit their use in some critical applications. For example, HFCs have long atmospheric life and high GWP, which do not meet the requirements of environmental protection. 2-BTP contains Br, which is too toxic and can cause harm to the human body. And the boiling point of PEMP is too high, hard to vaporize, which has impact on fire efficiency. Therefore, the above fire-extinguishing agents will be phased out in the future ${ }^{8-10}$.

Considering the drawbacks of these Halon substitutes, we have attempted to assess the possibility of using the environmentally friendly Iodinated alkanes as the Halon replacements and found that $\mathrm{CF}_{3} \mathrm{I}$ has a FEC of $3.0 \mathrm{vol} \%$ on n-heptane-air flame in a cup burner, which is similar to that of Halon 1301. Besides, $\mathrm{CF}_{3} \mathrm{I}$ is a new type of environmentally friendly $(\mathrm{GWP}<5, \mathrm{ODP}=0.008)$ alternative refrigerant and insulating gases with low toxicity, and $\mathrm{CF}_{3} \mathrm{I}$ also has good compatibility with the material. At present, the reaction kinetics of $\mathrm{CF}_{3} \mathrm{I}$ and $\mathrm{OH}^{*}$ have been investigated by using $\mathrm{Ab}$ initio calculation in a published paper ${ }^{11}$ which analyzed the formation enthalpy of the main reaction product HOI. Therefore, a further study on the initial pyrolysis reaction mechanism of $\mathrm{CF}_{3} \mathrm{I}$ is essential to evaluate the fire-extinguishing performance of this potential Halon substitute.

In this paper, the thermal decomposition mechanism of $\mathrm{CF}_{3} \mathrm{I}$ has been simulated by DFT with high precision quantum mechanics, and the subsequent reaction channels between $\mathrm{CF}_{3} \mathrm{I}$ and hydroxyl and hydrogen radicals have been calculated, which reveals the fire-extinguishing mechanism of this halogenated hydrocarbon containing iodine. Furthermore, the FEC of methane-air flame was measured to compare the fire-extinguishing performance of $\mathrm{CF}_{3} \mathrm{I}$ with HFCs. The results show that the fire-extinguishing performance of $\mathrm{CF}_{3} \mathrm{I}$ is better, even equal to that of Halon 1301. Therefore, we believe that $\mathrm{CF}_{3} \mathrm{I}$ has the potential to be used as a substitute of Halon for clean fire-extinguishing agents.

\section{Experimental and computational details}

\section{Calculation method}

In this paper, the Gaussian ${ }^{12}$ software package was used to study the thermal decomposition and fireextinguishing mechanism of $\mathrm{CF}_{3} \mathrm{I}$ by means of $\mathrm{Ab}$ initio quantum chemistry and DFT. The geometrical configuration optimization and vibration analysis of all stationary points involved in the reactions were obtained at the B3LYP/LanL2DZ level, and at the same level group, the relationship between reactants, products, intermediates and transition states (TS) was analyzed by using the theory of intrinsic reaction coordinate (IRC), and the correctness of each reaction path was verified. For the analysis for transition states, TS, QST2 and QST3 methods are employed when necessary. In order to obtain more accurate energy value, a more accurate method was used to calculate the single point energy of the stationary point optimized in the reaction at the level of CCSD/LanL2DZ basis set, and the accurate energy barrier value was obtained. All bond dissociation energies (BDEs) and energy barriers are corrected by zero point energy (ZPE).

In addition, on the basis of calculating the energy barrier of reaction path, the classical variational transition state theory (CVT) method, which is the most widely used in VTST, is used to calculate the reaction rate constants of each reaction path under the condition of considering Eckart tunneling effect, to further verify the possibility of each reaction path. The above calculation was completed by the Kisthelp ${ }^{13}$ package.

\subsection{Experimental method}

\subsubsection{Thermal decomposition analysis}

The thermal decomposition of $\mathrm{CF}_{3} \mathrm{I}$ (Yuji Tech, 99\%) was conducted in a quartz tube reactor under argon (Tianjin sizhi gas Co. Ltd, 99.9\%) flow (Fig.S1 ). In the experiment, $\mathrm{CF}_{3} \mathrm{I}$ was first premixed with the argon carrier gas in a mixing chamber, and their entering flow rates were adjusted separately by standard mass flowmeters. At the outlet of the chamber, samples were extracted for GC-MS (Thermo Fisher Scientific, Trace 
1310) instrument equipped with a DB-VRX column (Agilent, $30 \mathrm{~m}$ x $0.25 \mathrm{~mm}$ i.d., $1.4 \mathrm{um}$ film thickness). Then, $\mathrm{CF}_{3} \mathrm{I}$ was further carried into the tubular furnace, and its residence time was regulated by the gas flowing rate. The residence time was chosen to be $10 \mathrm{~s}$ and the volume fraction of $\mathrm{CF}_{3} \mathrm{I}$ was set as $20 \%$. The pyrolysis temperature ranged from 200 to 800 . After the thermal paralysis in the quartz tube, the decomposition products were analyzed by GC-MS. At different pyrolysis temperatures, the sampling and GCMS detection were repeated three times at a time interval of $30 \mathrm{~min}$, to ensure the reliable and reproducible of the results. The temperature was increased at a ramping rate of $5 / \mathrm{min}$ to the next targeting temperature and maintained stable for $30 \mathrm{~min}$.

\subsubsection{Fire extinguishing concentration measurement}

The $\mathrm{FEC}$ of $\mathrm{CF}_{3} \mathrm{I}$ for extinguishing methane-air flame and propane-air flame were measured by the cup burner (Fig.S2 ) method according to ISO14520-1 and NFPA 2001 standards $^{14,15}$. Volumetric flow rates of synthetic air (Tianjin sizhi gas Co. Ltd, $\mathrm{O}_{2} 20.9 \%, \mathrm{~N}_{2} 79.1 \%$ ) and gas fuel were fixed at $40 \mathrm{~L} / \mathrm{min}, 356$ $\mathrm{mL} / \mathrm{min}$ (methane), and $118 \mathrm{~mL} / \mathrm{min}$ (propane), respectively, to achieve a visible flame length of $80 \mathrm{~mm}$. After the flame was pre-burned for $60 \mathrm{~s}$, the extinguishing agent of $\mathrm{CF}_{3} \mathrm{I}$ was delivered into the flame burner, until flame blow-off occurred. The mean FEC was determined based on five consecutive test trial results. All the flow meters deployed in this paper were calibrated by the soap-film method or the drainage method before the experiments, and the total uncertainty of FEC obtained by the experiment was estimated as $5 \%$. The flame extinguisher was recorded by using a high-speed camera (Phantom Miro LAB110) which operated at 500 frames per second, with an exposure time of $40 \mu \mathrm{s}$.

\section{Results and discussion}

\subsection{Experimental measurement of thermal decomposition products}

To evaluate thermal stability and possible fire-extinguishing performance, the thermal decomposition products of $\mathrm{CF}_{3} \mathrm{I}$ are firstly analyzed. In the high-temperature condition, the $\mathrm{CF}_{3} \mathrm{I}$ should be thermally degraded into some products that may react with the $\mathrm{OH}$. and $\mathrm{H}$. radicals in the flame and thus restrain the chain reaction of combustion to a certain degree.

According to the thermal decomposition study of HFO-1336mzz(E) by Zhang ${ }^{16}$, considering the convergence of decomposition rate at $10 \mathrm{~s}$ and the short time of fire extinguish process, the residence time of $10 \mathrm{~s}$ is selected for thermal decomposition analysis. Considering the low molecular weight of $\mathrm{CF}_{3} \mathrm{I}$, its decomposition into organic products is difficult, and the decomposition temperature should be relatively high. Therefore, the initial temperature of this experiment was set at $200^{\circ} \mathrm{C}$. The upper limit of thermal decomposition was set at $800^{\circ} \mathrm{C}$.

Fig. 1 shows that the decomposition of $\mathrm{CF}_{3} \mathrm{I}$ started at $300^{\circ} \mathrm{C}$. When the temperature reaches $400^{\circ} \mathrm{C}$, silver particles are produced. Purple gas first appeared at the tube outlet at $500^{\circ} \mathrm{C}$, and a large quantity of silver

particles accumulated. The decomposition process stopped at around $700^{\circ} \mathrm{C}$, producing large amounts of solids. The solid silver particles were characterized by XRD (Fig.S3 ) and proved to be iodine. GC/MS analysis of the exhaust gas (Fig.S4 ) shows that organic products were observed. 


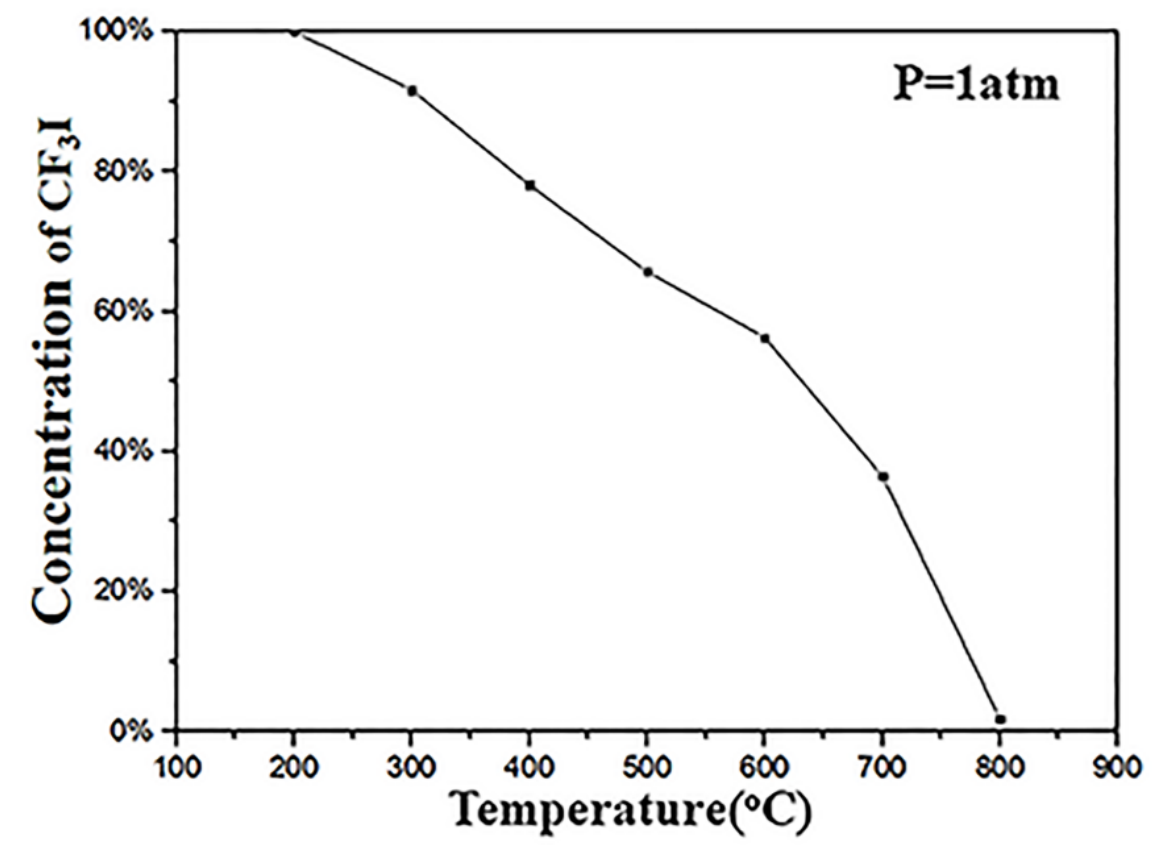

Fig.1. The decomposition process of $\mathrm{CF}_{3} \mathrm{I}$.

\subsection{Thermal decomposition mechanism of $\mathrm{CF}_{3} \mathrm{I}$}

The computational results of geometric optimization, frequency and energy analysis of the $\mathrm{CF}_{3} \mathrm{I}$ molecule as shown inFig.2. which suggest that the sum of electron and thermodynamic energy of the molecule corrected by ZPE is -347.737 Hartree, and there is no imaginary frequency in the molecule, indicating the reliability and stability of the investigated $\mathrm{CF}_{3} \mathrm{I}$ molecule. Besides, the bond angles of $2 \mathrm{~F}-1 \mathrm{C}-5 \mathrm{I}$ and $4 \mathrm{~F}-1 \mathrm{C}-5 \mathrm{I}$ in molecule have different bond lengths, suggesting the asymmetric structure of the molecule. And as listed in Table.1. The dissociation energy of 1C-5I $\left(42.581 \mathrm{kcal} \cdot \mathrm{mol}^{-1}\right)$ bond is far lower than those of other chemical bonds in $\mathrm{CF}_{3} \mathrm{I}$ molecule, indicating that this chemical bond is relatively weak and easy to break, leading to the formation of $\mathrm{CF}_{3} *$ radicals, which can interrupt the chain reaction of combustion and to achieve the purpose of fire-suppression. Furthermore, a comparison of the calculated bond energy of $\mathrm{CF}_{3} \mathrm{I}$ with that reported in the reference ${ }^{17}$ is presented in Table.S1, implying the reliability of DFT computations in this work. 


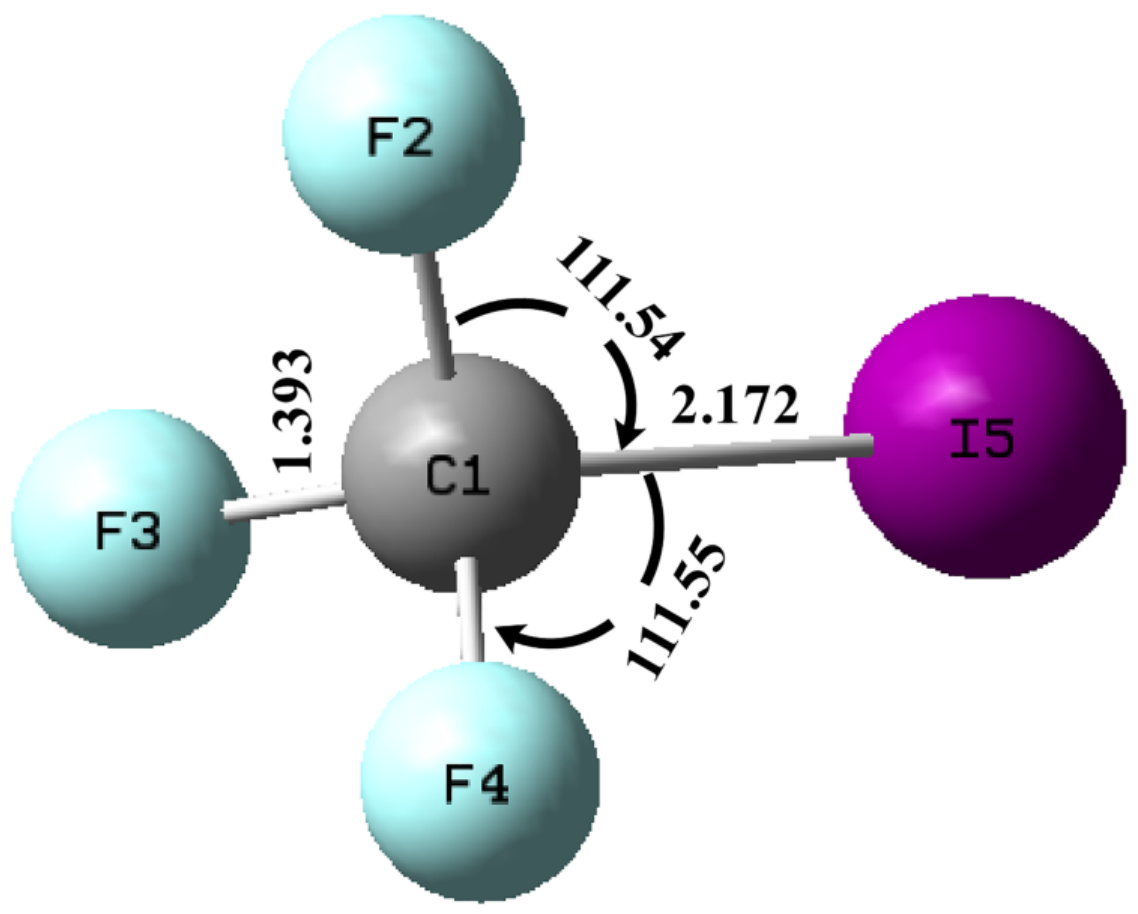

Fig. 2. Geometries of $\mathrm{CF}_{3} \mathrm{I}$ optimized at the B3LYP/LanL2DZ level of theory.

\begin{tabular}{ll}
\hline Table.1. BDEs of $\mathrm{CF}_{3} \mathrm{I}$ calculated by Gaussian 16 at CCSD/LanL2DZ//B3LYP/LanL2DZ theory level. & Table.1. BDEs \\
Bonds & Bonds \\
C-F & $\mathrm{R}(1,2)$ \\
& $\mathrm{R}(1,3)$ \\
C-I & $\mathrm{R}(1,4)$ \\
\hline
\end{tabular}

The thermal decomposition of $\mathrm{CF}_{3} \mathrm{I}$ consists of three pathways. The detailed decomposition path of $\mathrm{CF}_{3} \mathrm{I}$ was shown in Fig.3. All energy barriers were calculated by $\mathrm{kcal} \cdot \mathrm{mol}^{-1}$. Fig.S5 shows the geometric structures for the reactants, transition states, intermediate, and products involved in all calculated reactions (Including thermal decomposition and fire0extinguishing reaction channels) as optimized at the B3LYP/6-311++G (d, p) level. 


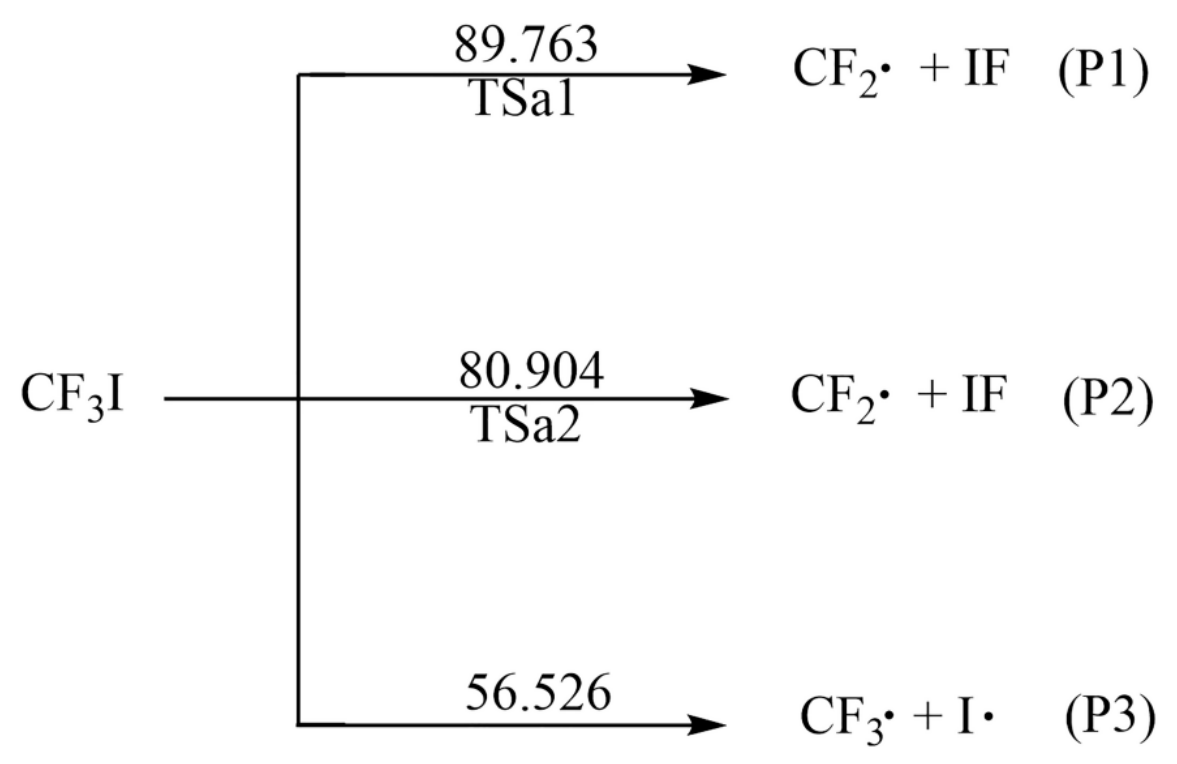

Fig. 3. Decomposition path of $\mathrm{CF}_{3} \mathrm{I}$ at the B3LYP/LanL2DZ level of theory.

During $\mathrm{CF}_{3} \mathrm{I}$ dissociation, two possible products can be formed when different bonds break. The most favorable is that $\mathrm{CF}_{3} \mathrm{I}$ can break the C-I bond to form $\mathrm{CF}_{3} \cdot+\mathrm{I}$, and the reaction barrier is $57.526 \mathrm{kcal} \cdot \mathrm{mol}^{-1}$. In this process, the length of $\mathrm{C}-\mathrm{I}$ bond gradually increases from $2.172 \mathrm{~A}$ of $\mathrm{CF}_{3} \mathrm{I}$ to $2.559 \mathrm{~A}$ until the fracture. In addition, two kinds of isomerization of $\mathrm{CF}_{3} \mathrm{I}$ can occur to produce the same substance, $\mathrm{CF}_{2}{ }^{*}+\mathrm{IF}$. One of the lower energy barrier is that atom $\mathrm{I}$ on atom $\mathrm{C}$ is transferred to an atom $\mathrm{F}$ of atom $\mathrm{C}$, and the product $\mathrm{CF}_{2}{ }^{*}+\mathrm{IF}(\mathrm{P} 2)$ is formed through the transition state TSa2, and the reaction energy barrier is 80.904 $\mathrm{kcal}^{*} \mathrm{~mol}^{-1}$. In this process, atom $\mathrm{F}$ on molecule $\mathrm{CF}_{3} \mathrm{I}$ is close to atom I. The I atom and $\mathrm{F}$ atom gradually combine and separate from the $\mathrm{CF}_{3} \mathrm{I}$ molecule to form a triplet of difluorocarbine $\mathrm{CF}_{2}{ }^{*}$ and iodine fluoride. The other is that $\mathrm{CF}_{3} \mathrm{I}$ generates product $\mathrm{P} 1$ through the transition state TSa1 with an energy barrier of $89.763 \mathrm{kcal}^{*} \mathrm{~mol}^{-1}$. The potential energy curve of the decomposition path of $\mathrm{CF}_{3} \mathrm{I}$ is shown in Fig.4 . It can be seen that the energy barriers of C-I bond fracture are all lower than that of C-F bond fracture, that is, the generation of $\mathrm{CF}_{3}{ }^{*}$ from C-I bond fracture is more likely to occur kinetically. The reaction rate constants of each decomposition path of $\mathrm{CF}_{3} \mathrm{I}$ at $1 \mathrm{~atm}$ and at different temperatures (280-2000K) are shown in Fig.5 . It can be seen that the rate constants of C-I bond homolysis reaction are all higher than that of C-F bond at different temperatures, which further indicates that C-I bond fracture is easier than C-F bond from the perspective of reaction rate. 


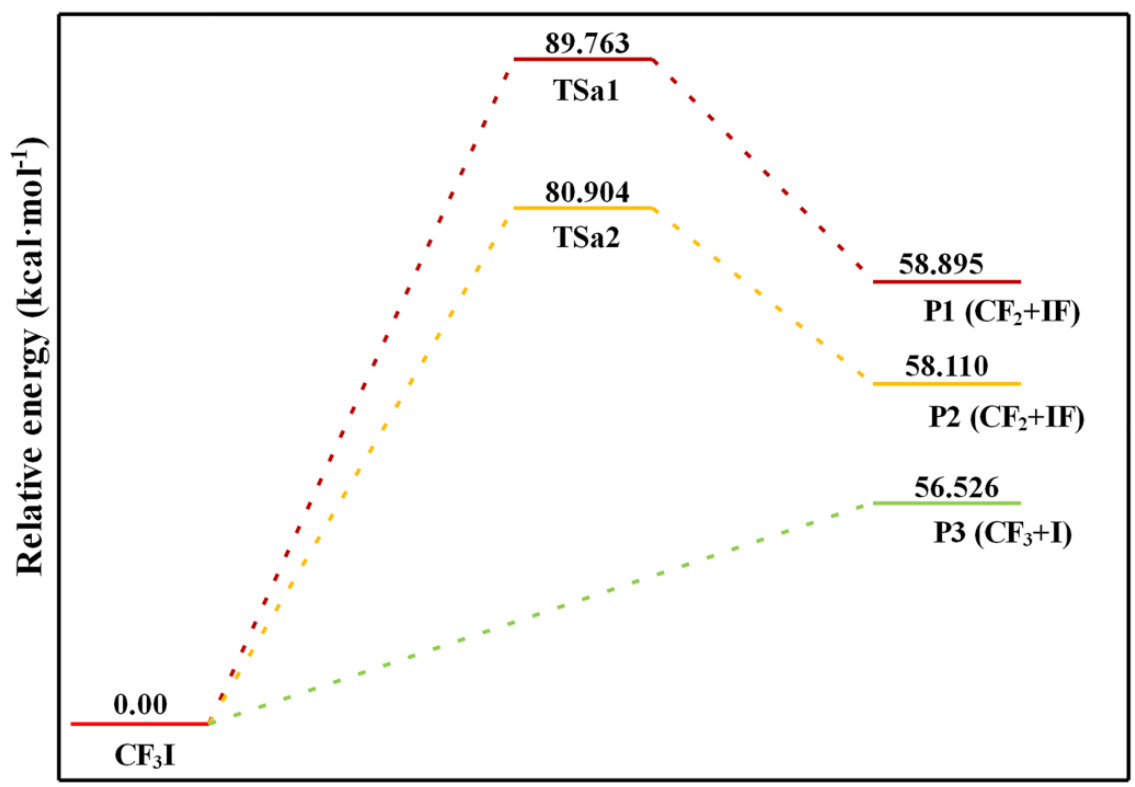

Reaction process

Fig. 4. Energy diagram of $\mathrm{CF}_{3} \mathrm{I}$ decomposition pathways obtained at the B3LYP/LanL2DZ level.

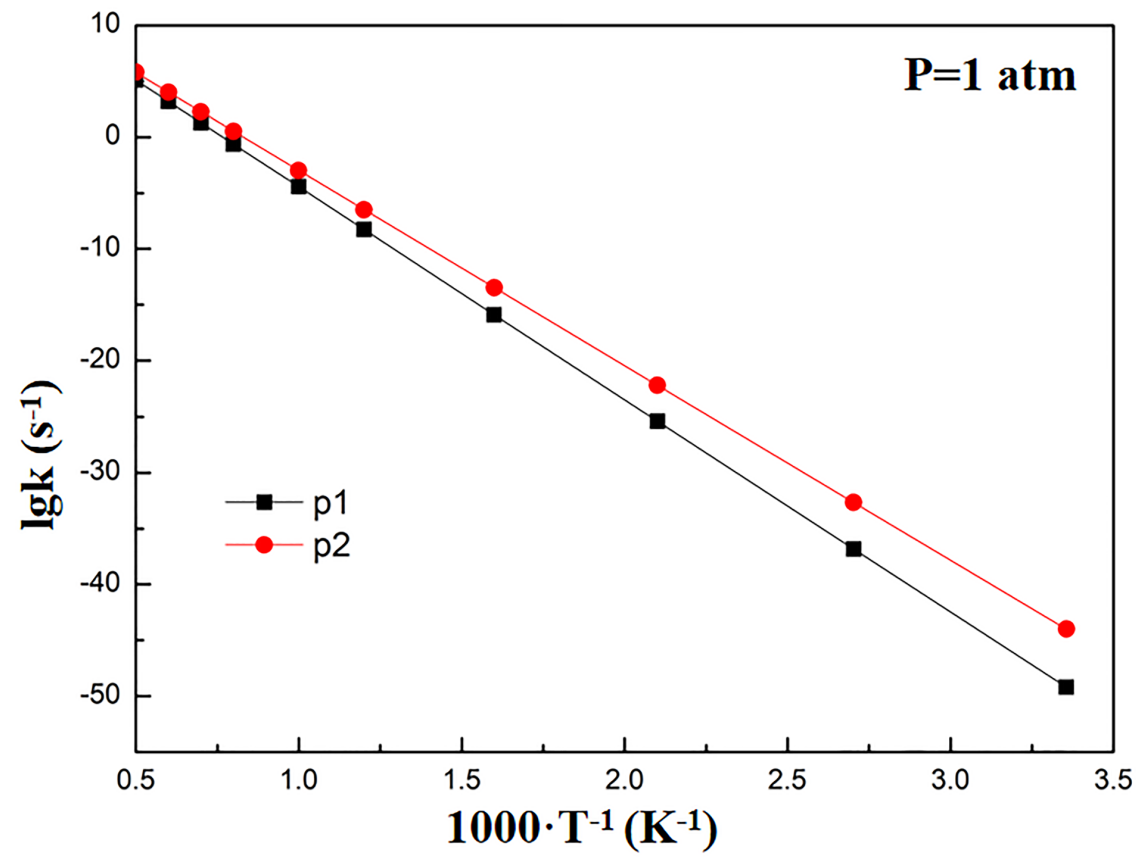

Fig. 5. Reaction rate constant of thermal decomposition pathway 1 of $\mathrm{CF}_{3} \mathrm{I}$. 


\subsection{Fire extinguishing performance of $\mathrm{CF}_{3} \mathrm{I}$}

Considering the above physiochemical characteristics and thermal decomposition products, $\mathrm{CF}_{3} \mathrm{I}$ may be a candidate for clean fire-extinguishing agent. Therefore, the $\mathrm{FEC}$ of $\mathrm{CF}_{3} \mathrm{I}, \mathrm{HFO}-1336 \mathrm{mzz}(\mathrm{E})$ and three HFCs were determined by using the cup-burner method involving methane/propane fuel. And the reliability of our experimental measurement was verified ${ }^{14}$ by comparing our measured FEC value $(9.70 \mathrm{vol} \%)$ for propane-air flame with that tested by the standard ISO 14520-1-2006 Part 8 (9.7vol\%). As listed in Table.2, $\mathrm{CF}_{3} \mathrm{I}$ exhibits the lowest FEC (3.61vol\%) for extinguishing the propane-air flame, even lower than that of Halon $1301(3.8 \mathrm{vol} \%-4.3 \mathrm{vol} \%)$ measured by Fumiaki ${ }^{18}$. For propane-air flame, the FEC performance of $\mathrm{CF}_{3} \mathrm{I}$ is much better than three HFCs and HFO-1336mzz(E). For extinguishment of methane-air flame, the FEC of $\mathrm{CF}_{3} \mathrm{I}$ is also the lowest (3.42vol\%), which is comparable to that of Halon 1301 (2.9vol\%-4.0vol\%). Therefore, the fire-extinguishing performance of $\mathrm{CF}_{3} \mathrm{I}$ is obviously better than those of HFCs and is comparable to that of Halons.

Table. 2. Flame-extinguishing concentration of $\mathrm{CF}_{3} \mathrm{I}$ and three typical HFC extinguishants. Type of agents

$\mathrm{CF}_{3} \mathrm{I}$

HFO-1336mzz(E)

HFC-125

HFC-116

HFC-236a
Table. 2. Flame-extinguishing concentration of $\mathrm{CF}_{3} \mathrm{I}$ and three typical HFC extinguishants. FECs for methane-air flame ( $\operatorname{vol} \%)$

3.42

5.46

8.47

6.92

5.19
Table. 2. Flame-extinguishing concentration of $\mathrm{CF}_{3} \mathrm{I}$ and three typical HFC extinguishants. FECs for propane-air flame (vol\%)

3.61

5.89

9.70

9.34

6.51

A high-speed camera was used to record the change of flame shape during the extinction of methane-air flame. The structures of the flame in different time nodes during the fire-extinguishing process were shown inFig.S6 , in which the time nodes were defined as 10s after the last time changing the concentration of the agent as the starting point (to wait the new ratio mixture of extinguishant and air getting into the cup-burner), and the flame being completely extinguished as the end point. As the time went by, it can be found that the flame lost stability and rapidly shocked, then the flame was suspended upward, finally the suspended flame completely detached from the cup, and the flame extinguished quickly. This process is similar to that of HFC-236fa, which also suggests that $\mathrm{CF}_{3} \mathrm{I}$ has potential as Halon replacement 。

\subsection{Theoretical analysis of fire extinguishing mechanism}

Extinguishing mechanism of fire extinguishing agent actually includes physical and chemical extinguishing mechanism. Physical extinguishing mechanism is realized by reducing temperature and isolating oxygen, etc., while chemical extinguishing mechanism refers to the capture and depletion of active radicals of hydroxyl and hydrogen by reactants required for combustion reaction. Highly active free radicals and molecular fragments generated by the pyrolysis of fire extinguishing agents can capture a large number of essential free radicals $\mathrm{OH} \cdot$ and $\mathrm{H} \cdot$ in the combustion reaction to block the combustion reaction and achieve the purpose of fire extinguishing ${ }^{19}$. Based on the low boiling point of $\mathrm{CF}_{3} \mathrm{I}$ at 1 atmosphere, it can be inferred that $\mathrm{CF}_{3} \mathrm{I}$ will vaporize rapidly at flame temperature and absorb heat at the same time, which indicates that $\mathrm{CF}_{3} \mathrm{I}$ has the possibility of physical fire extinguishing. In addition, all of the above decomposition reactions are endothermic reactions, which can also reduce the temperature of the fire site. Based on the geometry of $\mathrm{CF}_{3} \mathrm{I}$, the most likely fire-extinguishing free radical produced by $\mathrm{CF}_{3} \mathrm{I}$ is $\mathrm{CF}_{3}$. At present, a large number of literatures have reported its reaction mechanism of capturing flame radicals such as $\mathrm{OH} \cdot$ and $\mathrm{H}^{20-23}$, which confirmed its fire extinguishing effect. Therefore, in this section, the research on the mechanism of fire suppression in $\mathrm{CF}_{3} \mathrm{I}$ is mainly devoted to exploring the formation path of $\mathrm{CF}_{3}$. in $\mathrm{CF}_{3} \mathrm{I}$. The research method is the same as the study of thermal decomposition mechanism. The calculated fire-extinguishing mechanism is shown inFig. 6 . 

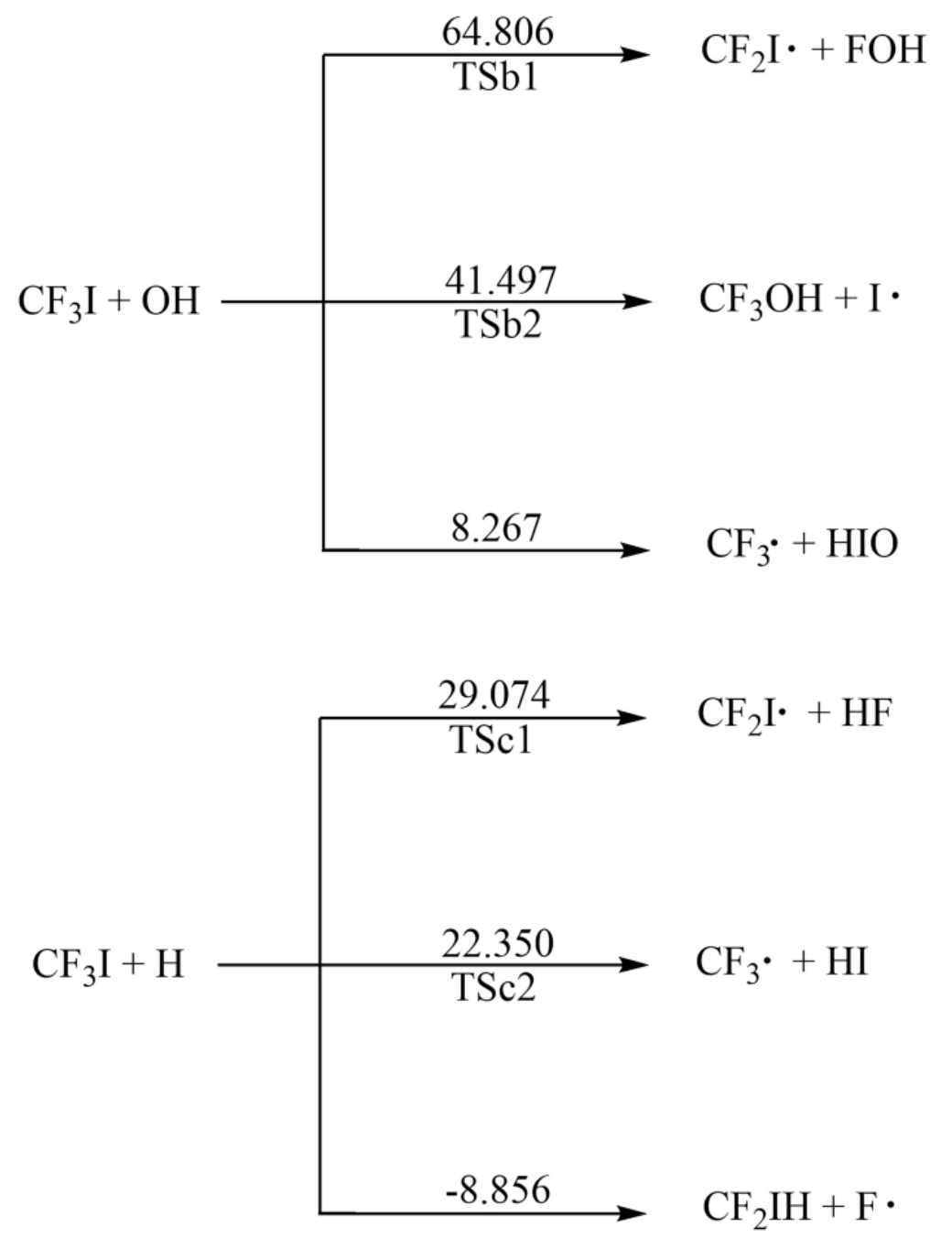

Fig. 6. Pathways $\mathrm{CF}_{3} \mathrm{I}$ reacts with the free radicals in fire flame.

When $\mathrm{OH}$ radical and $\mathrm{CF}_{3} \mathrm{I}$ approach each other, $\mathrm{OH}$ radical interacts with different atoms of the $\mathrm{CF}_{3} \mathrm{I}$ molecule in the reaction to form various possible products. As the first reaction step, the $\mathrm{O}$ atom of the $\mathrm{OH}$ can directly absorb the $\mathrm{F}$ atoms of $\mathrm{CF}_{3} \mathrm{I}$ molecule through the transition state TSb1 to form $\mathrm{CF}_{2} \mathrm{I} \cdot+$ $\mathrm{FOH}(\mathrm{P} 4)$, with the barrier height of $64.806 \mathrm{kcal} \cdot \mathrm{mol}^{-1}$. When the $\mathrm{O}$ atom of the $\mathrm{OH}$ attacks the $\mathrm{C}$ atom of $\mathrm{CF}_{3} \mathrm{I}, \mathrm{CF}_{3} \mathrm{OH}+\mathrm{I}(\mathrm{P} 5)$ may be formed through the transition state TSb2. In the process of reaction, $\mathrm{O}$ atom of $\mathrm{OH}$ attacks $\mathrm{C}$ atom of $\mathrm{CF}_{3} \mathrm{I}$, causing it to get rid of the $\mathrm{I}$ atom, and the energy barrier is $41.497 \mathrm{kcal}^{*} \mathrm{~mol}^{-1}$. The last reaction step between $\mathrm{CF}_{3} \mathrm{I}$ and $\mathrm{OH}$ radical is the most likely to occur, with no intermediate transition state. $\mathrm{CF}_{3} \mathrm{I}$ directly deatoms I to generate $\mathrm{CF}_{3} *+\mathrm{HIO}(\mathrm{P} 7)$ with a small energy barrier of $8.267 \mathrm{kcal}^{*} \mathrm{~mol}^{-1}$. According to the above calculation results, the potential energy curve of the reaction path between $\mathrm{CF}_{3} \mathrm{I}$ and $\mathrm{OH}$ radical is shown in Fig.7 . The results show that in the $\mathrm{CF}_{3} \mathrm{I}+\mathrm{OH}$ reaction, the I atom extraction channel may be dominant from the perspective of kinetics, and $\mathrm{CF}_{3} \mathrm{I}$ is more likely to generate $\mathrm{CF}_{3}$ fire-extinguishing radical. 


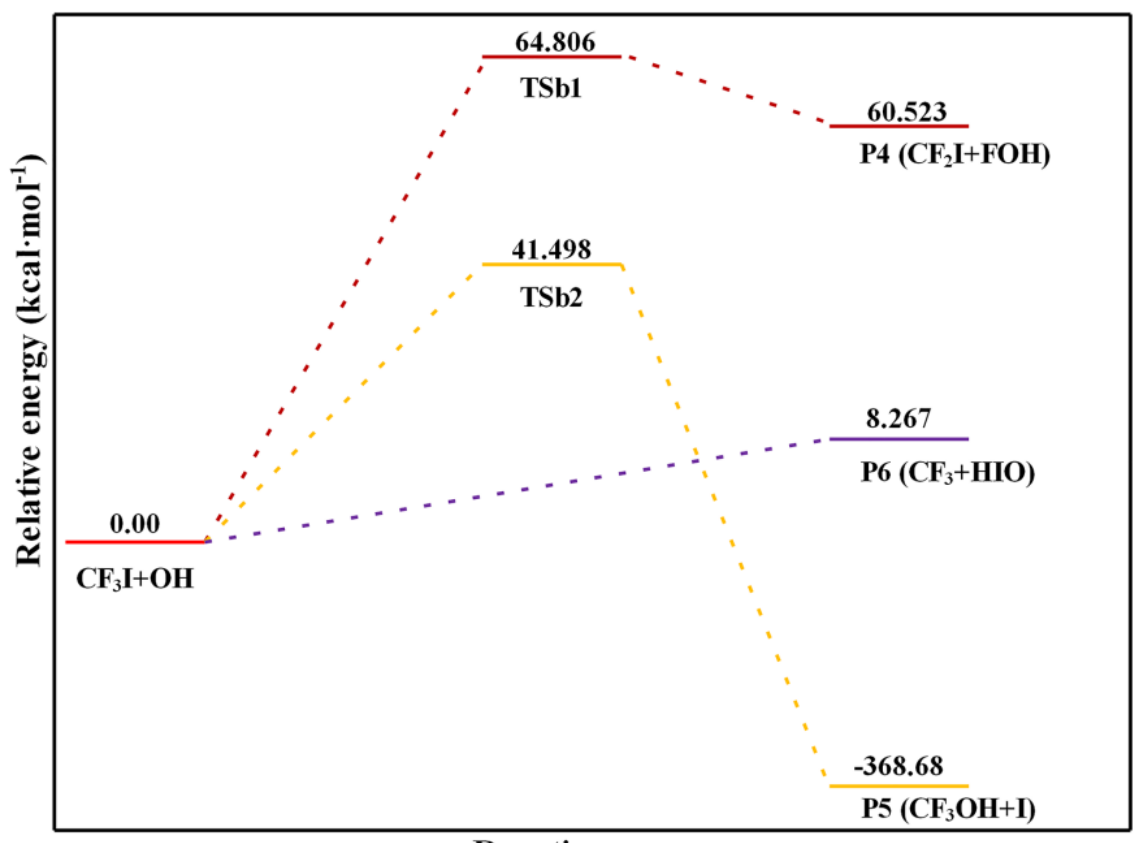

Reaction process

Fig.7. Energy profiles for the reaction of $\mathrm{CF}_{3} \mathrm{I}+\mathrm{OH}$ obtained at the B3LYP/LanL2DZ level.

Similar to the reaction of the $\mathrm{OH}$ radical with $\mathrm{CF}_{3} \mathrm{I}$ discussed above, the reaction of the $\mathrm{H}$ radical with $\mathrm{CF}_{3} \mathrm{I}$ can also produce three different products when they are close to each other. However, part of the reaction of $\mathrm{CF}_{3} \mathrm{I}+\mathrm{H}$ is exothermic, which may affect the fire-extinguishing effect in physical aspects. But in the process of the reaction can produce effective fire-extinguishing free radicals $\mathrm{CF}_{3}$. For example, $\mathrm{CF}_{3} \mathrm{I}$ generates $\mathrm{CF}_{3}$. $+\mathrm{HI}$ through the transition state TSc2, and the energy barrier height is $22.350 \mathrm{kcal} \cdot \mathrm{mol}^{-1}$. The specific transformation process is that $\mathrm{CF}_{3} \mathrm{I}$ first dissolves one of the $\mathrm{F}$ atoms to form the transition state TSc2, then the hydrogen atom attacks the $\mathrm{I}$ atom of $\mathrm{CF}_{3} \mathrm{I}$, and finally the separated $\mathrm{F}$ atom returns to its original position. In the $\mathrm{CF}_{3} \mathrm{I}+\mathrm{H}$ reaction, there is another reaction path that $\mathrm{H}$ radical directly extracts fluorine from $\mathrm{CF}_{3} \mathrm{I}$ through TSc1 to form $\mathrm{CF}_{2} \mathrm{I}^{*}+\mathrm{HF}$, and the energy barrier height is $29.074 \mathrm{kcal}^{*} \mathrm{~mol}^{-1}$. In the final reaction path, hydrogen atoms directly attack $\mathrm{C}$ atoms, and one of the fluorine atoms falls off to form $\mathrm{CF}_{2} \mathrm{IH}+\mathrm{F}^{*}$ with an energy barrier of $8.856 \mathrm{kcal}^{*} \mathrm{~mol}^{-1}$.

According to the above calculation results, the potential energy curve of the reaction path between $\mathrm{CF}_{3} \mathrm{I}$ and hydrogen is shown in Fig.8 . The results show that hydrogen can extract I atom from $\mathrm{CF}_{3} \mathrm{I}$ with a small energy (less than $30 \mathrm{kcal}^{*} \mathrm{~mol}^{-1}$ ), which leads to generate effective fire-extinguishing free radical $\mathrm{CF}_{3}{ }^{*}$. In addition, the reaction rate constants of each reaction path between $\mathrm{CF}_{3} \mathrm{I}$ and active radicals at 1 atm and different temperatures (280-2000K) are shown in Fig.9 . It can be seen that the rate constants of the C-I bond homolysis reaction are all higher than that of the $\mathrm{C}-\mathrm{F}$ bond homolysis reaction at various temperatures, which is consistent with the thermal decomposition analysis of $\mathrm{CF}_{3} \mathrm{I}$. Thus, it is further verified that C-I bond breaks more easily than C-F bond. From the perspective of reaction kinetics, it is shown that $\mathrm{CF}_{3} \mathrm{I}$ is easy to form $\mathrm{I}$ and $\mathrm{CF}_{3}$ extinguishes free radicals, which explains the good extinguishing performance of $\mathrm{CF}_{3} \mathrm{I}$. 


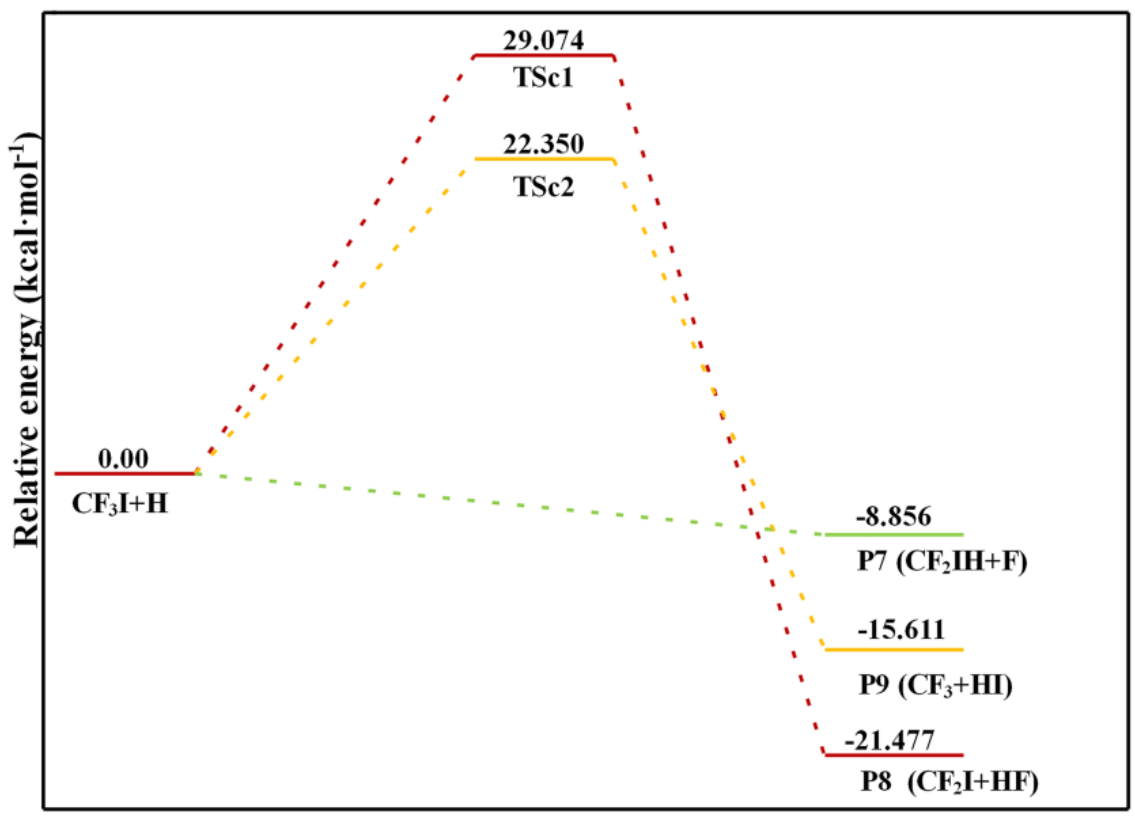

Reaction process

Fig.8. Energy profiles for the different pathways in $\mathrm{CF}_{3} \mathrm{I}+\mathrm{H}$ reaction obtained at the B3LYP/LanL2DZ level.

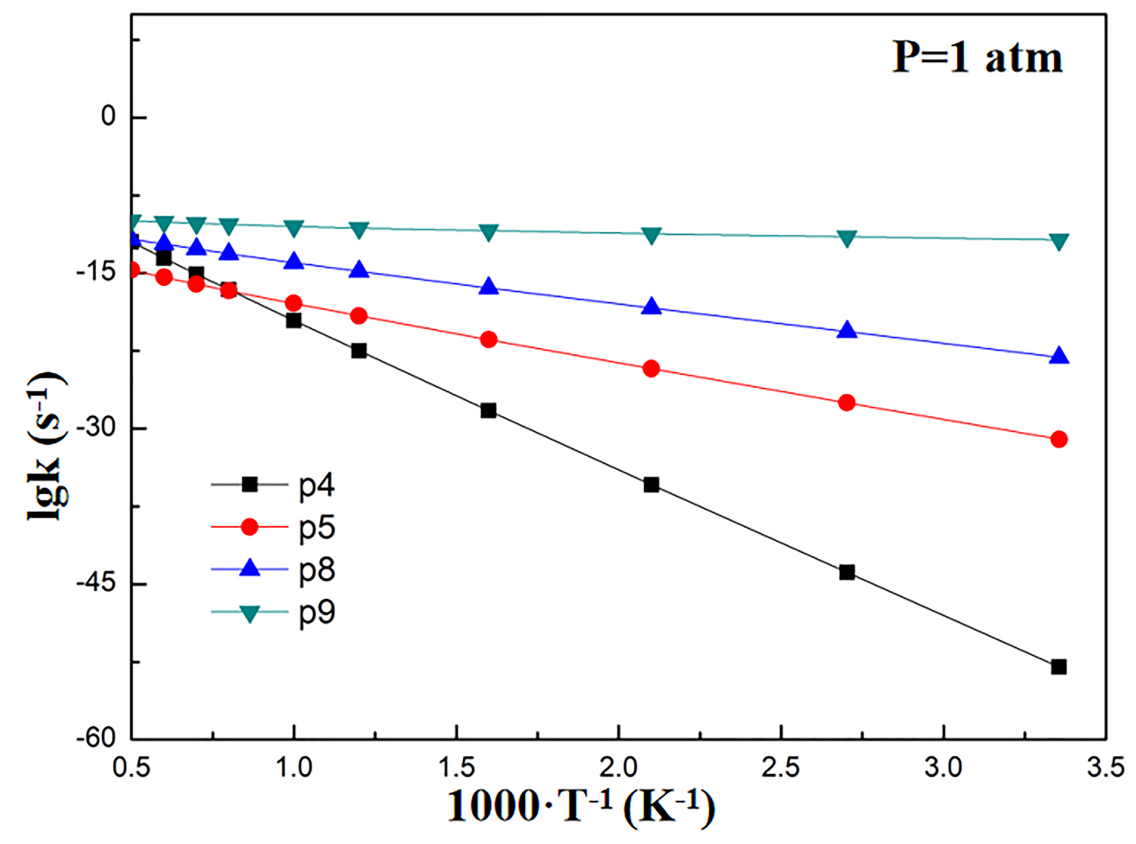

Fig.9. Reaction rate constants of each reaction path between $\mathrm{CF}_{3} \mathrm{I}$ and active radicals at $1 \mathrm{~atm}$ and different temperatures (280-2000K). 


\section{Conclusion}

In view of the environmental friendliness, low boiling point and low toxicity of $\mathrm{CF}_{3} \mathrm{I}$, it could be a potential Halon substitute for fire-extinguishing agent in aircraft. In this paper, DFT calculations were performed to theoretically investigate the thermal decomposition and fire-extinguishing mechanism of $\mathrm{CF}_{3} \mathrm{I}$, which suggest that $\mathrm{CF}_{3} \mathrm{I}$ and its decomposition products can further react with active $\mathrm{OH}$. and $\mathrm{H}$ - radicals existed in flame through various pathways. Remarkably, through DFT calculation and reaction kinetics analysis, the fireextinguishing radicals $\mathrm{CF}_{3}$. and $\mathrm{I}$. are more easily generated during the interaction between $\mathrm{CF}_{3} \mathrm{I}$ and flame, which can react with the active $\mathrm{OH}$. and $\mathrm{H}$ - radicals to achieve the purpose of rapidly extinguishing fire.

To explore its actual fire-extinguishing effect, we also measured the $\mathrm{FEC}$ of $\mathrm{CF}_{3} \mathrm{I}$ on methane-air flame. The experimentally measured $\mathrm{FEC}$ of $\mathrm{CF}_{3} \mathrm{I}$ on methane-air flame is $3.42 \mathrm{vol} \%$, which is lower than those of three HFCs and HFO-1336mzz(E), and is comparable to that of Halon 1301. Due to the pronounced fireextinguishing performance, environmental friendliness, and promising thermal stability and storability, the $\mathrm{CF}_{3} \mathrm{I}$ agent is a recommendable candidate for Halon, which is worthy of further evaluation and confirmation of its practical applications in fire suppression process.

\section{Declaration of Competing Interest}

The authors declare that they have no known competing financial interests or personal relationships that could have appeared to influence the work reported in this paper.

\section{Acknowledgments}

This work was sponsored by Science and Technology Research Project of Hebei Higher Education Institution (ZD2020138) and Open Fund of Key Laboratory of Civil Aviation Thermal Hazards Prevention and Emergency Response (RZH2020-KF-04). Tianjin Education Commission (2020KJ027), Scientific Research Foundation of Civil Aviation University of China (2020KYQD03).

Appendix. Supplementary materials

Supporting Information: Table.S1, Figs: S1-S6.

\section{References}

1. Li, K.; Kennedy, E. M.; Dlugogorski, B. Z., Gas-phase reaction of halon 1301 (CBrF3) with methane. Ind. Eng. Chem. Res.1999, 38 (9), 3345-3352.

2. Yu, H.; Kennedy, E. M.; Uddin, M. A.; Sullivan, S. P.; Dlugogorski, B. Z., Experimental and computational studies of the thermal decomposition of halon 1211. Int. J. Chem. Kinet. 2005,37 (3), 134-146.

3. Howe, R. F.; Thomson, S.; Yang, Y.; Lee, K.; Kennedy, E. M.; Dlugogorski, B. Z., Zeolite catalysts for Halon conversion. J. Mol. Catal. A: Chem. 2002, 181 (1-2), 63-72.

4. Chow, W. K.; Lee, E.; Chau, F.; Dyke, J., The necessity of studying chemical reactions of the clean agent heptafluoropropane in fire extinguishment. Archit. Sci. Rev. 2004, 47 (3), 223-227.

5. Xu, W.; Jiang, Y.; Ren, X., Combustion promotion and extinction of premixed counterflow methane/air flames by C6F12O fire suppressant.J. Fire Sci. 2016, 34 (4), 289-304.

6. Babushok, V. I.; Linteris, G. T.; Burgess Jr, D. R.; Baker, P. T., Hydrocarbon flame inhibition by C3H2F3Br (2-BTP). Combust. Flame.2015, 162 (4), 1104-1112. 
7. Orkin, V. L.; Louis, F.; Huie, R. E.; Kurylo, M. J., Photochemistry of bromine-containing fluorinated alkenes: Reactivity toward OH and UV spectra. J. Phys. Chem. A. 2002, 106 (43), 10195-10199.

8. Hodnebrog, Â.; Etminan, M.; Fuglestvedt, J. S.; Marston, G.; Myhre, G.; Nielsen, C. J.; Shine, K. P.; Wallington, T. J., Global warming potentials and radiative efficiencies of halocarbons and related compounds: A comprehensive review. Rev. Geophys. 2013,51 (2).

9. Zhou, X.; Chen, W.; Chao, M.; Liao, G., The study of thermal decomposition of 2-bromo-3, 3, 3trifluoropropene and its fire-extinguishing mechanism. J. Fluorine Chem. 2013,153, 101-106.

10. DiNenno, P. J.; Forssell, E. W., Clean agent total flooding fire extinguishing systems. In SFPE Handbook of Fire Protection Engineering, Springer: 2016; pp 1483-1530.

11. Berry, R.; Yuan, J.; Misra, A.; Marshall, P., Experimental and computational investigations of the reaction of OH with CF3I and the enthalpy of formation of HOI. J. Phys. Chem. A. 1998,102 (27), 5182-5188.

12. Frisch, M.; Trucks, G.; Schlegel, H.; Scuseria, G.; Robb, M.; Cheeseman, J.; Scalmani, G.; Barone, V.; Petersson, G.; Nakatsuji, H., Gaussian 16, Revision C. 01. Gaussian, Inc., Wallingford CT.

2016.

13. Canneaux, S.; Bohr, F.; Henon, E., KiSThelP: A program to predict thermodynamic properties and rate constants from quantum chemistry results. J. Comput. Chem. 2014, 35 (1), 82-93.

14. ISO 14520-Part 1, Gaseous Fire-extinguishing Systems-Physical Properties and

System Design, International Organization for Standardization (ISO),

2015.

15. National Fire Protection Association. 2018. NFPA 2001 Standard on Clean Agent Fire

Extinguishing Systems. National Fire Protection Association, Quincy, Massachusetts.

16. Zhang, H.; Wang, Y.; Wang, X.; Zhou, S.; Yu, R.; Liao, Y.; Li, J.; Tan, Z., Thermal Decomposition Mechanism and Fire-Extinguishing Performance of trans-1, 1, 1, 4, 4, 4-Hexafluoro-2-butene: A Potential Candidate for Halon Substitutes.J. Phys. Chem. A.2020, 124 (28), 5944-5953.

17. Luo, Y., The Data Handbook of Chemical Bond Energies. Science Press, Beijing: 2005.

18. Takahashi, F.; Katta, V. R.; Linteris, G. T.; Babushok, V. I., A computational study of extinguishment and enhancement of propane cup-burner flames by halon and alternative agents. Fire Saf. J.2017, 91 , 688-694.

19. Xie, D. E., HFC-227ea Fire-Extinguishing System. Fire ence and Technology 1999 .

20. Takahashi, K.; Yamamori, Y.; Inomata, T., A Kinetic Study on the Reaction of CHF3 with H at High Temperatures. J. Phys. Chem. A.1997, 101 (48), 9105-9110.

21. Srinivasan, N. K.; Su, M.-C.; Sutherland, J. W.; Michael, J. V.; Ruscic, B., Reflected shock tube studies of high-temperature rate constants for $\mathrm{OH}+\mathrm{NO}_{2}-\mathrm{HO}_{2}+\mathrm{NO}$ and $\mathrm{OH}+\mathrm{HO}_{2}-\mathrm{H}_{2} \mathrm{O}+\mathrm{O}_{2}$. J. Phys. Chem. A. 2006, 110 (21), 6602-6607.

22. Fukaya, H.; Ono, T.; Abe, T., New fire suppression mechanism of perfluoroalkylamines. Journal of the Chemical Society, Chem. Commun. 1995, (12), 1207-1208.

23. Murphy, A.; Farmer, A.; Horrigan, E.; McAllister, T., Plasma destruction of ozone depleting substances. Plasma Chem. Plasma Process. 2002, 22 (3), 371-385. 

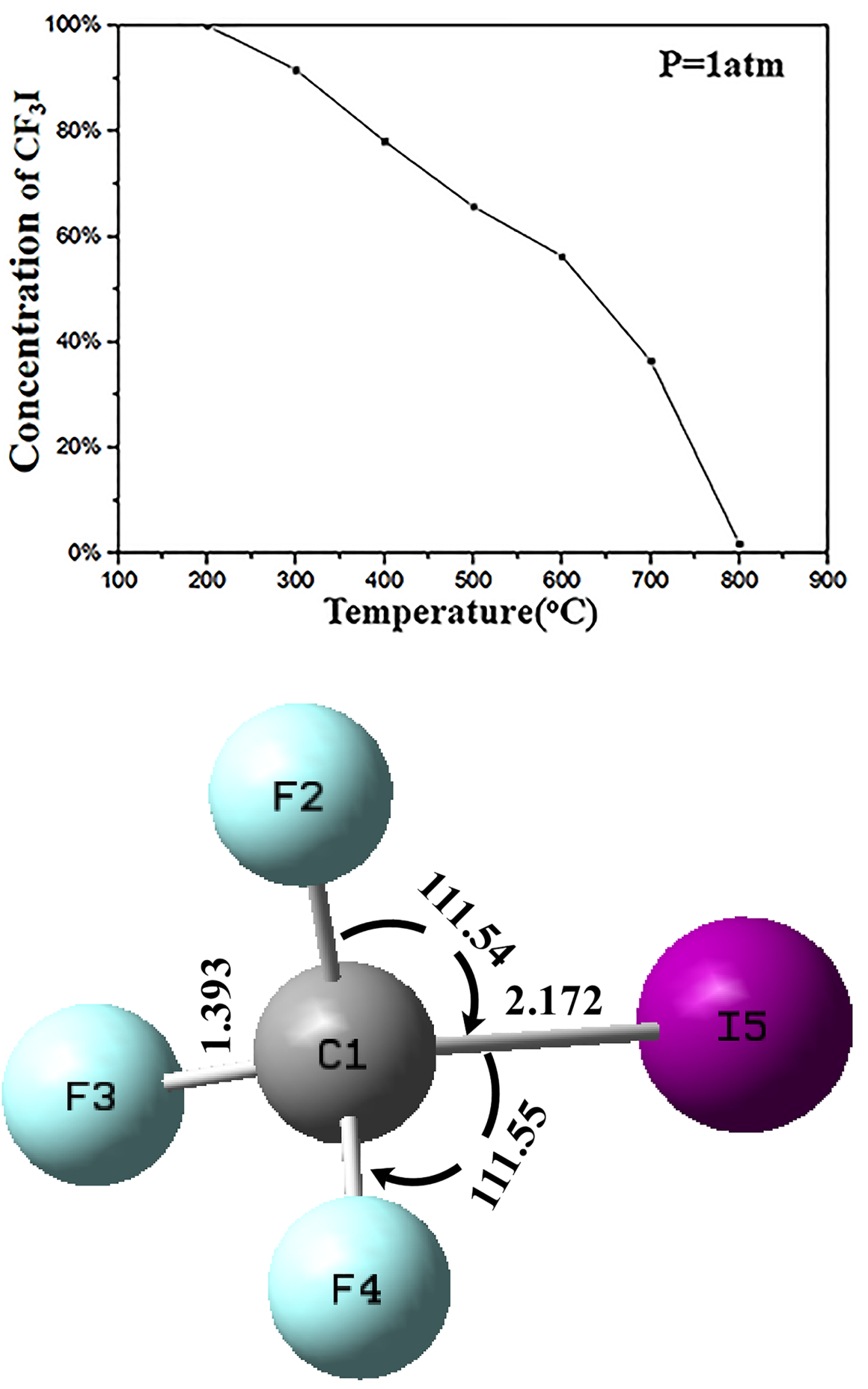

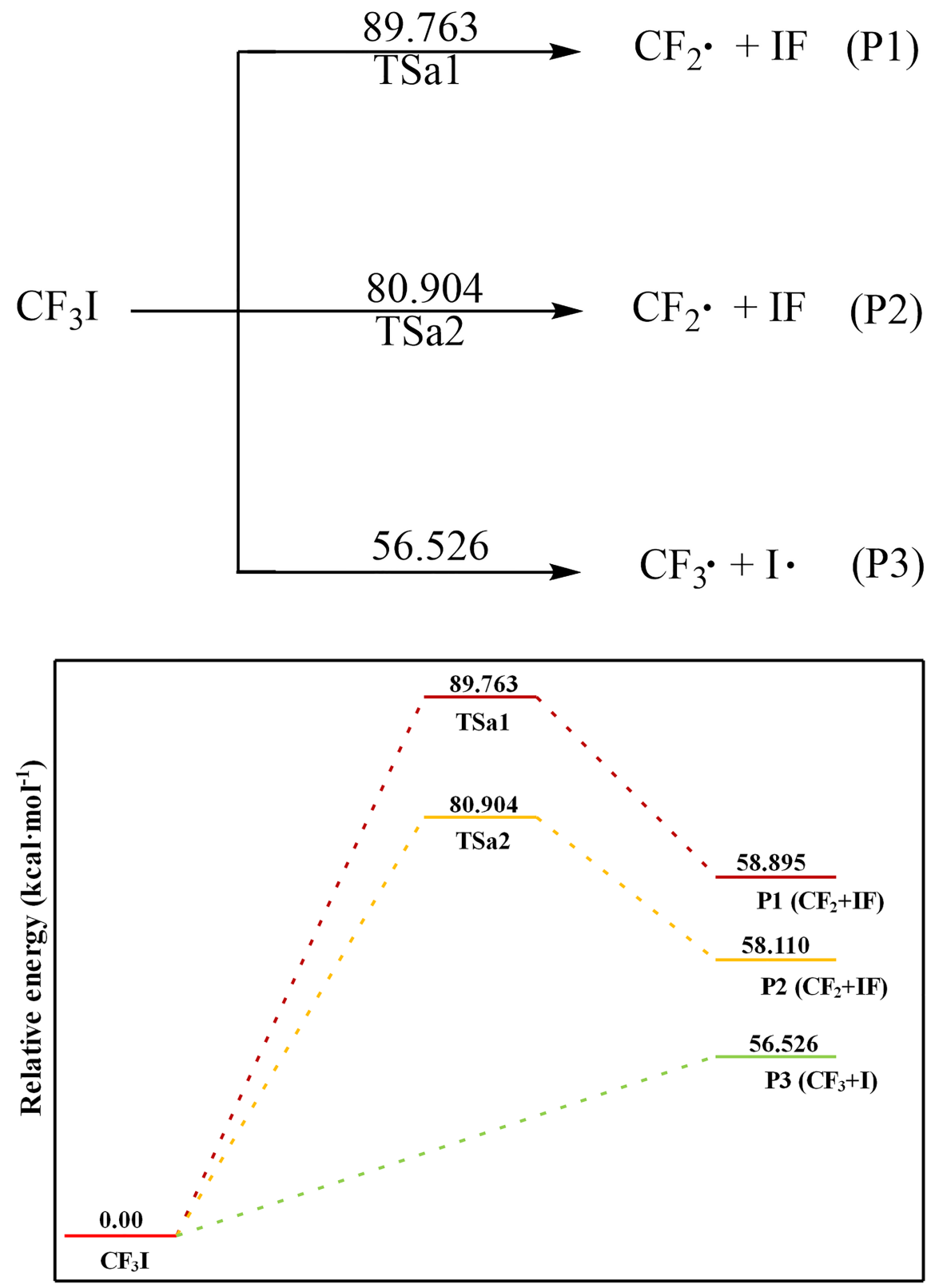

Reaction process 


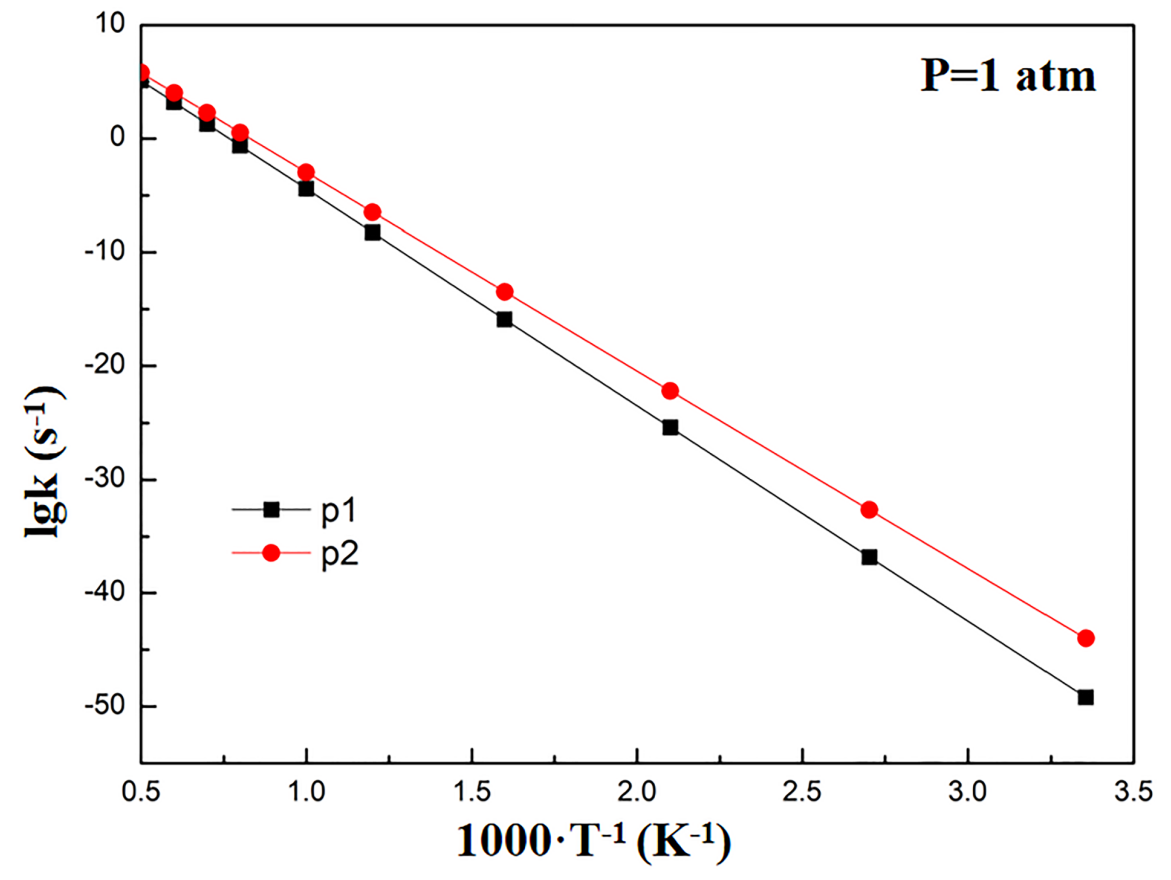



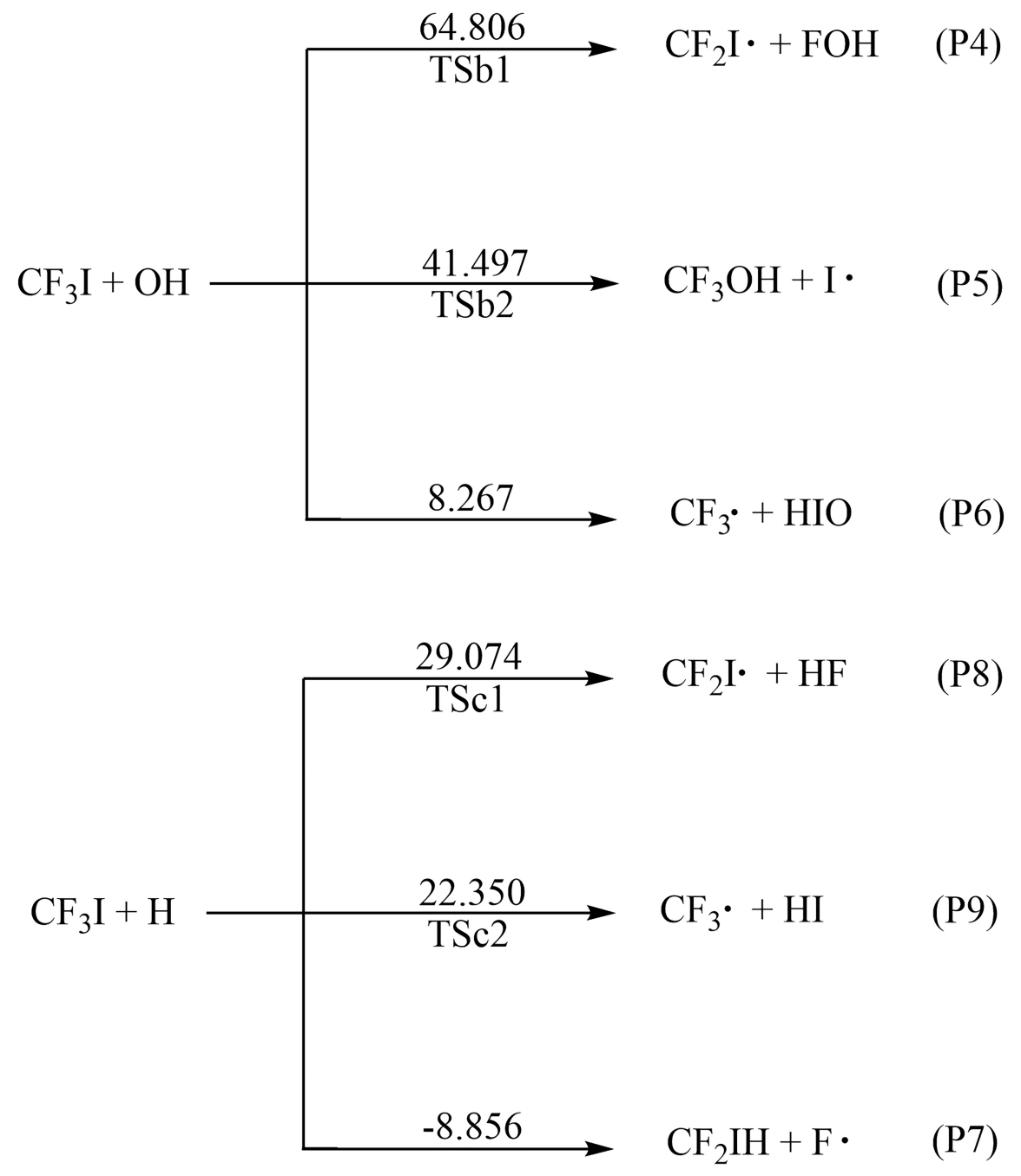


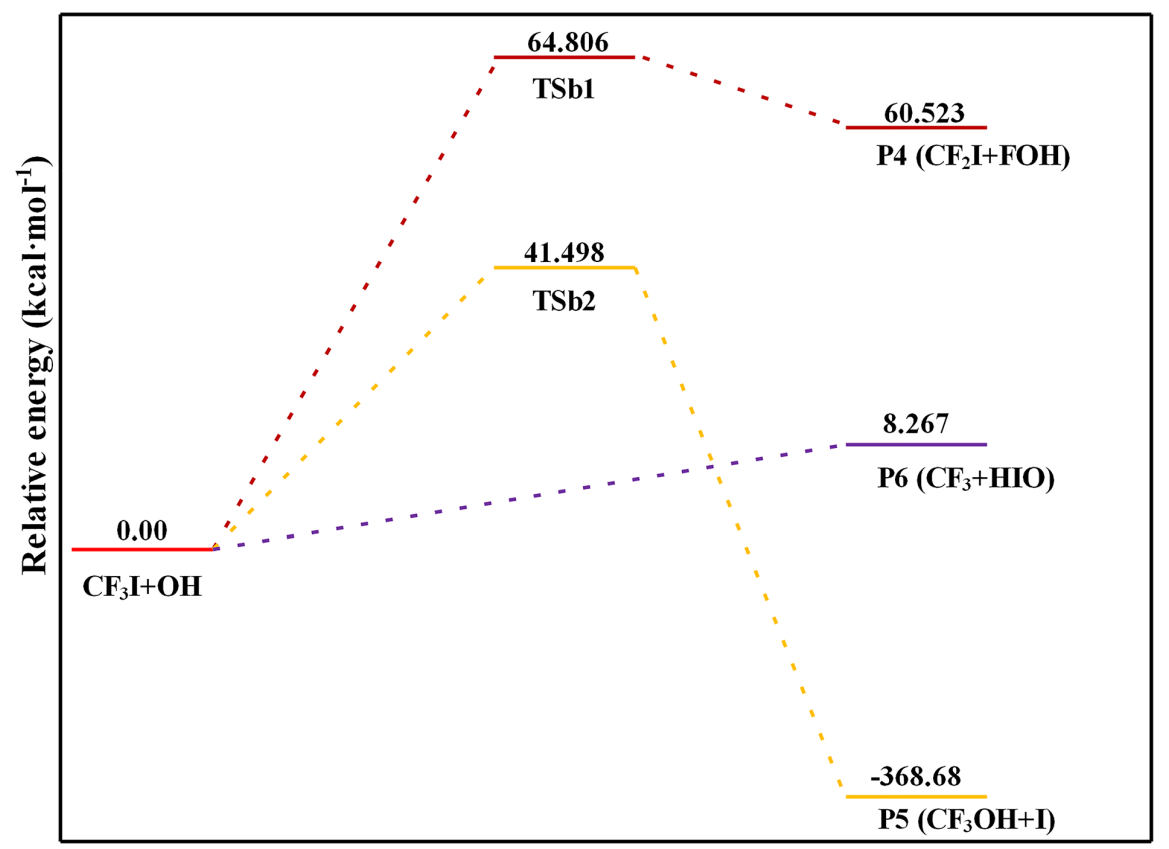

Reaction process

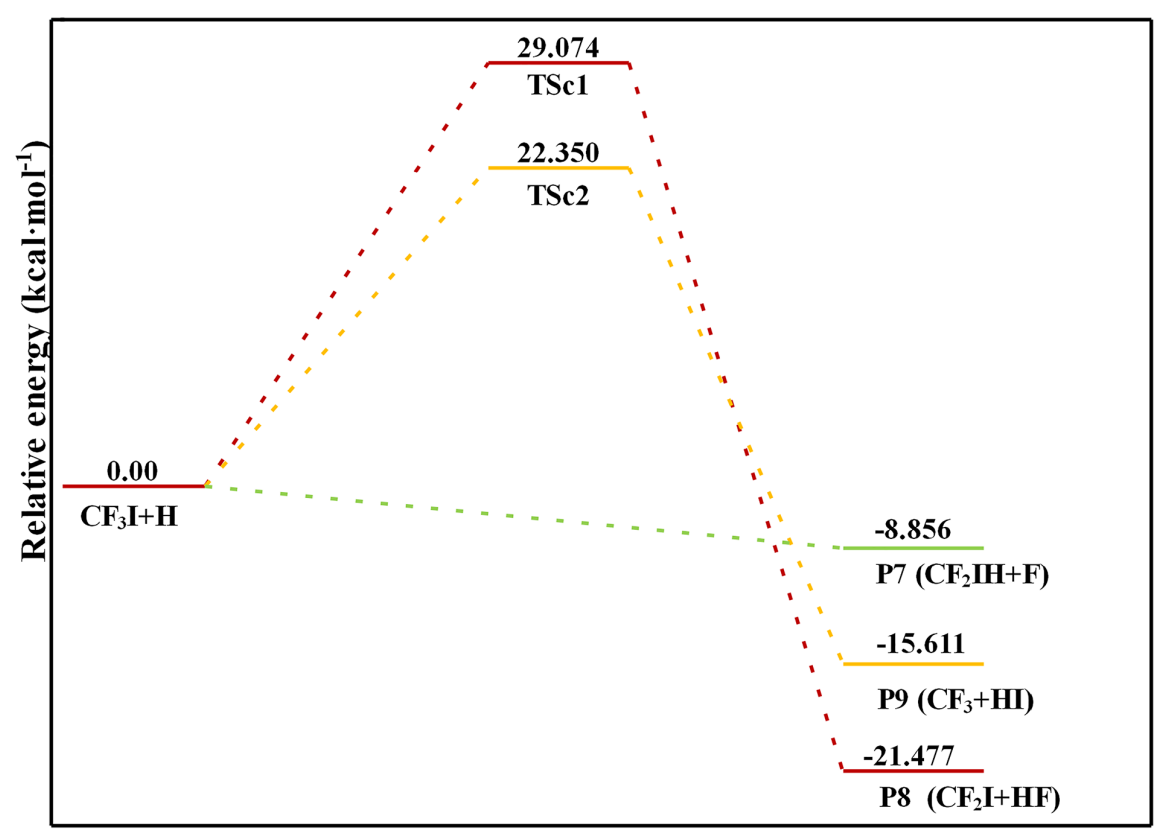

Reaction process 


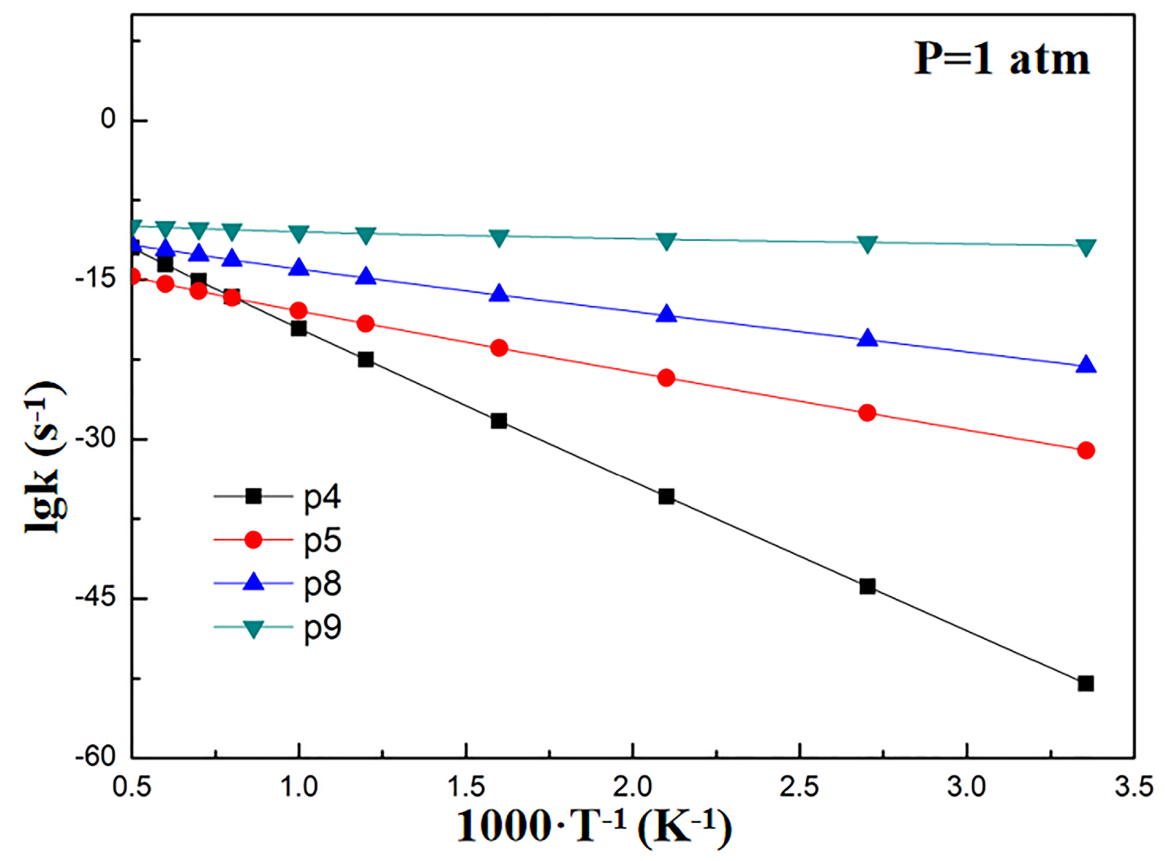

